\title{
Examining the Impact of ICT on Sustainable Development: A Data-Driven Narrative
}

\author{
Gautam Ramasubramanian \\ Center for Inclusive Digital \\ Enterprise, New Zealand \\ gsr30@uclive.ac.nz
}

\author{
Aijaz A. Shaikh \\ University of Jyväskylä, Finland \\ aijaz.a.shaikh@jyu.fi
}

\author{
Ravishankar Sharma \\ University of Canterbury, New Zealand \\ Centre for Inclusive Digital Enterprise, \\ New Zealand \\ rsharma@ ceide.org
}

\begin{abstract}
Considering the challenges of sustainable development and the mixed prescriptions being offered by the use of digital technologies, we present a datadriven narrative of how ICT development impacts the sustainable growth of economies. The analysis is based on historical panel data from 39 economies across the developed and developing economies. The industrystandard CRISP-DM methodology was applied as it is flexible, robust, and offers a practical approach for data analytics. The findings reveal that there are differentiated outcomes in terms of sustainable growth among high-income and low-income economies. This poses legitimate questions as to whether low-income economies will be able to meet the UN's Sustainable Development Goals by 2030 through the intermediation of ICT.
\end{abstract}

\section{Introduction and background}

The research goal of this paper is to investigate how Information \& Communications Technologies (ICTs) can address sustainability; specifically, energy consumption and productivity without compromising the well-being of society. . In this age of digital lifestyles and the global ubiquity, availability, and adoption of ICTs, processes, and tools, it is not always clear whether ICT leads to the creation of a development trajectory [13]; [26]. While ICTs may be seen as a part of a wider concern for global development, their role in fulfilling sustainable development has not been adequately understood in terms of driving policy and meaningful action [19]; [23]; [1]. In this context, sustainability refers to the usage of appropriate means to lessen the impact of the depletion of natural resources and maintain ecological balance while promoting human and economic growth [24]. A simplifying dimension is the productive usage of energy resources and minimization of carbon footprints or $\mathrm{CO} 2$ emissions. The concept of green ICT involves minimizing the carbon footprint and ICT waste whilst optimizing energy productivity. This brings about environmental well-being.

Historically, the role of ICT has been mixed in terms of sustainable development. Since this paper seeks to examine sustainable ICT, we selectively review prior empirical research in the area. For example, a study by [10] involved collecting primary data in the form of questionnaires addressed to various stakeholders in the educational industry. Significant barriers include a lack of funding and managerial support, a lack of interest/participation by stakeholders, little or no awareness of green ICT among decisionmakers, nonchalance about ICT's impact on sustainability, and a lack of regulation, among other policy variables.

The relationship between ICT development and human development has received widespread scholarly attention. There is considerable agreement in the scholarly literature that it is not just advancements in technology that can lead to the betterment of human life, as there are other factors which impact socioeconomic development. The extent to which these technologies can be used to harness improvements in social well-being should also be taken into account. A data-driven narrative could show that ICT development can enhance developments in human life when objectives are clearly met, and proper policies are adopted. However, the nuanced trade-offs, demand for resources, and other potential downsides need to be considered in a situational context [6].

With numerous studies having analyzed the impact of ICT on economic growth, the common belief among positivist scholars [cf 1, 2, 3, 4, 6, ... that ICT brings real economic growth, especially in developed economies, has been questioned [13].. Moreover, it should be noted that an increase in economic growth does not necessarily translate to an increase in human development since inequality or poverty, for instance, can rise even if the economy is performing well. However, it is understood that human development is necessary if ICT and technological development is to happen [19]. [4] examines the impact and influence of 
ICT development on human development and economic growth in 27 European countries by acquiring data from the Eurostat database. In order to understand the impact of human development, the study uses the UNDP's Human Development Index (HDI), which comprises income, education, and health, and the Education Index (EI). ICT variables which include ICT in households, firms, and civic society. In short, the study uses fifteen variables, nine of which are structural and six of which pertain to policies. It is revealed that different EU countries have achieved different levels of human development and economic progress based on their degrees of ICT development, meaning that it is indispensable for most developing economies to implement ICT for human and economic progress.

In most of the above-cited studies use selective metrics to develop an understanding of the impact of ICT in contributing to a sustainable society. In a similar fashion, this paper discusses the relationship of ICT and sustainability concerning the productive use of energy and other resources without sacrificing environmental well-being. A data-driven approach is adopted by selective mining measures from 50 economies over the period from 1995 to 2013. Our findings indicate that ICT-developed economies are more inclined to adopt sustainable energy resources. A recent industry example is Microsoft's green data centres which use significantly fewer energy resources $^{1}$. Although the implementation and acceleration of ICT in underdeveloped countries as well as technology transfers from developed to undeveloped countries have been suggested by [27], these models have not been investigated by scholars.

In the remainder of the paper, we discuss the Sustainable Society Index (SSI) and discourses on ICT for development, the research methodology, findings and discussion, and finally the theoretical contributions and policy implications.

\section{ICT4D and the theory of modernization}

Modernization theory holds that since ICTs have been essential elements of development. This has led scholars to draw from the resemblances that exist between this theory and the current assumptions of ICT4D discourses. Given this, there is a critical conviction of the need to transfer technologies (ICTs) from the more developed North to the South to bring about inclusive global participation in the information society.

\footnotetext{
${ }^{1}$ https://www.weforum.org/agenda/2020/09/microsoftproject-natick-underwater-data-center-scotland
}

After an extensive review of scholarly research, [13] concludes that theories of modernization are based on the notion that technological knowledge, tools, and techniques developed in the West should be transferred to less developed economies to achieve mutual benefit. [13] also notes considerable agreement among scholars that aid given to poor countries connected to requirements for political, structural, and social changes could lead to economic growth. Crucial with regard to the analysis of ICTs is the fact that [14] emphasized the importance of transferring technologies from industrialized North to the South in order to replicate progress. Due to the significant digital gap between the North and South, international institutions, such as the World Bank and the ITU, have been concerned with digitalizing the Global South. These institutions share the belief that if poorer regions of the world are not integrated into the information society, they will face further obstacles to their development. For example, in the UN's initial Millennium Development Goals (MDGs, now known as SDGs), ICTs were promoted as tools to catalyse economic development and thereby to fight poverty [12]. The UN 2030 Agenda for Sustainable Development also recognizes the great potential of ICTs and calls for significantly increased access to them, which will play a crucial role in supporting the implementation of all the sustainable development goals (SDGs; cf. [9]).

Emerging ICTs have greatly changed the world we live in. First, in the Global North, computerized systems have increased the efficiency of both the private and public sectors. However, some leading scholars argue that ICT for Development (ICT4D) has not been an absolute success [12, 13]. Development theory offers a valuable insight into how development practitioners believe they can achieve their aims and what concepts their aims are based on. Even though many studies on ICT4D exist, only a few of them discuss the meaning of development by drawing on development theory [2]; [25]. [19] showed that ICTs per se do not lead to development; the co-creation and distribution of competitive knowledge are required to bring this about.

Not only is the above perspective on the adverse impacts of ICTs limited in scope, it overlooks an increasingly important aspect of sustainability. Specifically, the negative impact on the environment has been "alarming" [3] and requires urgent redress. The advent of ICT at its incipient stage may not have foreseen this, but its quick adoption has subsequently led to environmental degradation. The critical consequences are climate change and more $\mathrm{CO} 2$ emissions, and circumventing the size of the carbon footprint caused by ICT is a challenge that has been barely discussed. Although ICT has drastically reduced 
physical commutes and promoted electronic means of transmission (by reducing paper-based products), thereby reducing greenhouse gas emissions, the effect of Green House Gas (GHG) emissions caused by ICT is still of concern. It is estimated that the proportion of the carbon footprint owing to ICT comes from data centres (18\%); personal computers, peripherals, and printers (57\%); and telecom infrastructure (25\%). Some of the key indicators concerning the reduction of the carbon footprint come from stakeholder action, IT changes, policies, and rules, and, most importantly, from their adoption processes. The paper concludes and offers a list of suggestions that would possibly alleviate the part of the carbon footprint impacted by ICT, and these include saving power (such as less energy consumption, turning off monitor/computers when unused). These factors can only be applied at an individual level, and these techniques are rather suggestions that might help in reducing the carbon footprint. The adoption mechanisms vary from country to country.

[5] analyzed the impact of ICT on environmental sustainability based on a set of predicted environmental indicators for 2020 and found that there is a significant chance of improving environmental impacts when certain adoption mechanisms are employed. The study was limited to the European Union. Indicators used to assess the environmental impact included the volume of transport to GDP, modal splits of transport, energy consumption (inclusive of the weight of renewable sources), GHG emissions, and non-recycled yet collected waste. The result was that the effect can be anywhere between $-20 \%$ to $+30 \%$. The study also suggests that ICT apps that make transportation more efficient, in turn, cause more energy consumption and GHG emissions. In order to alleviate the effects, the paper suggests e-materialization, intelligent transport systems, the restriction of electricity consumption, efficiency in electricity production and supply, ICTsupported applications for energy savings, renewable energy adoption, and ICT-supported waste management.

Another study [1] examined the impact of the acceleration of ICT on enhancing human development in 49 countries across Sub-Saharan Africa over the years ranging from 2000 to 2012. The indicators for the analysis included income levels, legal origin, religious affiliation, governance \& stability, openness to sea (overseas trade), and the country's wealth, while ICT factors included mobile phones, telephones, and internet penetration per 100 inhabitants. Certain control variables like GDP per capita, foreign aid, private domestic credit, foreign direct investment (FDI), and remittances were also considered. Their findings (through correlation analysis) showed that the post-
2015 sustainable agenda and policies designed to boost ICT development (mobile, internet, and telephone penetration), in turn, increase overall human development.

In spite of criticisms leveled at modernization theory and the doubts expressed as to how far its application really has helped in ending poverty in the Global South, the theory continues to exert a considerable influence over Western foreign policy on "development," in general, and on the deployment of ICTs, in particular. The essence of modernisation theory was the dualistic opposition between the North and the South and the need for the South to "catch up" with the North. The potential of ICTs may be significant, but its success depends on the details of implementation as the strategy of simply transferring "best-practice" from the North to the South is likely to fail.

\section{Using the CRISP-DM methodology}

[22] state 3 important considerations in narrative construction: 1) Narratives are interpretative rather than explanatory or predictive and tend to address the limits of traditional explanatory social science; 2) Narratives help scholars move beyond descriptions of a universalized, orderly world and connect with indigenous knowledge or experience that are unique to specific contexts - an intellectual idea emerging as "fallism"; 3) Narratives help build the required connectedness between the researchers and the practitioners which is revealing in insights about exceptions or counter-arguments. Scholars acknowledge the persuasive power of narratives for the purpose of communicating scientific knowledge to non-expert audiences through their ability to increase comprehension, interest and engagement. Additionally, it has been suggested that a narrative makes a topic much more real to the audience because it reframes the argument as a relatable message.

As we looked to develop narratives on the use of ICT, a data-driven approach was sought. The Cross Industry Process for Data Mining (CRISP-DM ${ }^{2}$ ) method was deployed since it is robust, sound and captures the entire range of the possible sequences in the data analytics process. It is well regarded in the data analytics procession as a standard that ensures "good outcomes". Furthermore, the model is iterative, and sequences can be carried out in different orders.

\footnotetext{
2 https://www.datasciencecentral.com/profiles/blogs/ crisp-dm-a-standard-methodology-to-ensure-a-goodoutcome
} 


\begin{tabular}{|c|c|c|c|c|}
\hline $\begin{array}{l}\text { Business } \\
\text { Understanding }\end{array}$ & Data Understanding & Data Preparation & $\begin{array}{l}\text { Medelling / } \\
\text { Analysis }\end{array}$ & Evaluation \\
\hline $\begin{array}{l}\text { ICT and SSI } \\
\text { background }\end{array}$ & $\begin{array}{l}\text { Initial data collection } \\
\text { from various sources }\end{array}$ & $\begin{array}{l}\text { Rationale for } \\
\text { inclusion of selected } \\
\text { variables (Extracted } \\
\text { from background } \\
\text { and literature) }\end{array}$ & $\begin{array}{l}\text { Variable } \\
\text { parameter } \\
\text { settings (IBM } \\
\text { SPSS) }\end{array}$ & $\begin{array}{l}\text { Evaluation of } \\
\text { the generated } \\
\text { results }\end{array}$ \\
\hline Literature reviews & $\begin{array}{l}\text { Data description (What } \\
\text { each variable indicates) }\end{array}$ & $\begin{array}{l}\text { Rationale for } \\
\text { countries selected } \\
\text { (To understand } \\
\text { disparities/similariti } \\
\text { es in high and low- } \\
\text { income countries) }\end{array}$ & $\begin{array}{l}\text { Correlation } \\
\text { analysis }\end{array}$ & $\begin{array}{l}\text { Inspiration and } \\
\text { insights from } \\
\text { literature }\end{array}$ \\
\hline Assessment of tools & $\begin{array}{l}\text { Data exploration } \\
\text { (Conducting a couple of } \\
\text { tests from the gathered } \\
\text { data) }\end{array}$ & $\begin{array}{l}\text { Exclusion of } \\
\text { countries that has } \\
\text { less or no data } \\
\text { points (i.e. data } \\
\text { cleaning) data } \\
\text { integration. }\end{array}$ & $\begin{array}{l}\text { Assessment of } \\
\text { the generated } \\
\text { model }\end{array}$ & $\begin{array}{l}\text { Recommendati } \\
\text { on and } \\
\text { limitations }\end{array}$ \\
\hline Project plan & $\begin{array}{l}\text { Data quality (Treating } \\
\text { null values) }\end{array}$ & Data integration & $\begin{array}{ll}--- \\
\end{array}$ & Conclusion \\
\hline
\end{tabular}

Figure 1: CRISP-DM steps

Figure 1 is a tabulation of the cyclic steps of CRISP-DM and the procedures within them. Note that while the starting point is a business understanding of an analytic problem and the end point is the deployment of either an analytic model or findings in terms of rules, procedures, etc., the CRISP-DM approach is iterative and cyclic. In other words, it is

ongoing and continuous.

The business understanding included background information and a summarization of the important terminology that is appurtenant to the study, as well as the elicitation of the requirements, objectives, and goals of the data analytics project. Much of the data understanding and gathering focused on background details of what ICT and SSI comprise, the way they are calculated, relevant background readings pertaining to the study, the assignment of tools that may be beneficial in highlighting details in the data, and the overall project plan, scope, and time constraints that should be taken into account.

The rational for the inclusion of certain variables and the selected countries is addressed in the data preparation and was carried out based on background studies and feature analyses. The unification of data from several sources was carried out to ensure coherency, and countries that had much less data to work with were excluded as part of the data cleaning process. Analyses were carried out using IBM SPSS, and the findings are discussed as part of the evaluation process. Correlogram charts were generated in $\mathrm{R}$ Studio. The findings were also compared with the extant literature review for corroboration and insights in order to craft a narrative.

The published sources listed below provided data for our analysis. They were authoritative and available in the public domain. By means of representative and convenience sampling, the set of countries were

selected for analysis. Following from the discourses on ICT for development and constrained by the availability of quality datasets from the United Nations, World Economic Forum, Sustainability Society Index, etc. (cf knoema.com appropriate indicators were collected for representative countries. Since the purpose of this paper was to construct a datadriven narrative which examined ICT impact on sustainability, the selection and use of extensive indicators for regression analysis was not required. Instead, the indicators selected were generally instructive of the relationship between ICT adoption, sustainability and measures of socio-economic wellbeing.

ICT development-related indicators (i.e., ICT access, ICT usage, and ICT skills) were scaled into ratings ranging from 0 to 10 .. The same applied to all the indicators that came from the SSI. ICT access included telephone, mobile, broadband, and computer access. With the formula used in [9], each parameter was equally weighted, and the indicator comprised 
$40 \%$ of the weight in calculating the overall index. Similarly, ICT use also included internet, broadband, and mobile usage in the appertaining country/economy. ICT skills were measured based on education enrolment ratios of the country/economy. The final index was calculated using the weighted average method $-40 \%$ for ICT usage and access and $20 \%$ for ICT skills [9]. These indicators were included as [3] posits that the highest proportion of the carbon footprint comes primarily from data centers, computer usage, and telecom usage.

The Sustainable Society Index provided some composite measures of socio-economic well-being. For instance, education was calculated based on enrolment ratios of the country in percentages. The healthy life indicator was computed by looking at life expectancy at birth in terms of the number of healthy life-years. Income distribution was arrived at by calculating the ratio of the incomes of the richest $10 \%$ and the poorest $10 \%$ of people in a country. Good governance was the cumulative value of the six worldwide governance indicators identified as the following: (1) voice and accountability, (2) political stability, (3) government effectiveness, (4) regulatory quality, (5) the rule of law, and (6) the control of corruption. These are World Bank indicators, and each of these indicators was assigned a value from -2.5 to 2.5 , meaning that the overall cumulative score could range from -15 to +15 .

Biodiversity was calculated by looking at ten-year changes in forest areas and sizes of protected land areas as percentages of the total land areas of a country. Renewable water resources were arrived at by taking the annual water withdrawals (m3 per capita) as percentages of the renewable water resources. A perplexing question was whether Greenhouse gas (GHG) emissions were a fair and appropriate measure of sustainability. Despite apparent limitations concerning equity between developed and developing, for our data-driven narrative, we calculated GHG emissions by looking at the amount of $\mathrm{CO} 2$ emissions (in metric tons) per capita per year in a country. The score for GHG was calculated as 10 -x with $\mathrm{x}$ being the number of metric tons. If the country emitted more than 10 metric tons, the value was assumed to be zero. This means that a higher score indicated fewer GHG emissions and vice versa. Renewable energy was arrived at by looking at the percentage of renewable energy production in terms of total energy production. The normalized score was derived by dividing this value by 10 [24].

Next, data retrieved from various Excel/CSV files were cleansed for missing values and integrated through Excel. Statistical analyses and charts were generated in IBM SPSS. First, countries were segregated based on their Gross National Income (GNI) per capita scores. Efforts were taken to ensure that data collected from various sources were complete so that data imputation could be reduced.

When considering missing values, the SSI data were exhaustive for all countries compared to the following years: 2006, 2008, 2010, 2012, 2014, and 2016. Furthermore, there were no missing values for the ICT data from high-income countries. The data included were from the following years: 2002, 2007, 2008, 2010, 2011, 2012, 2013, 2015, 2016, and 2017. However, there were 7 missing values for Burundi, 6 for Haiti, 2 for Guinea and Yemen, and 1 missing value for Malawi, Myanmar, and Nepal.

\section{Findings and discussion}

In high-income economies (as defined by [19] in terms of GDP per capita), education showed a moderate positive relationship with ICT development. This means that high-income countries are well informed and have the ability to exploit and assimilate ICT for the betterment of education [18]. Consequently, ICT (for instance, internet usage) offers self-directed learning with quality content, which underdeveloped economies lack access to. Research by [1] has also revealed that educational development happens not only in high income countries but also in developing countries with increased ICT diffusion.

Figure 2 summarizes the relationships between GHG emissions, renewal energy, and ICT development in the form of correlograms generated from panel data using R Studio. The noted naturalist Jane Goodall, in a recent documentary for the World Economic Forum , spoke about conservation as being a key sustainability measure. Among numerous indices of environmental well-being, e adopt GHG emissions and clean energy adoption as representative for the purpose of developing the narrative later in this section. Note that high-income economies (shown in the top chart) exhibit decreased GHG emissions and increased clean energy adoption owing to ICT development, and lowincome countries exhibit mixed behavior (shown in the bottom chart). Among low-income economies, education showed some correlation with ICT access. Educational levels could be improved with awareness, proper regulations, and participation. The study by [10] suggests that barriers to ICT implementation are owing to nonchalance towards sustainable measures, a lack of stakeholder participation, and funding issues. These have to be addressed on a contextual basis so as to obtain improvements. [1] study further revealed increases in human development (health, income, and education in 49 Sub-Saharan countries, indicating that 
ICT development can essentially increase educational enrolment rates. This applies to both developed and developing economies.

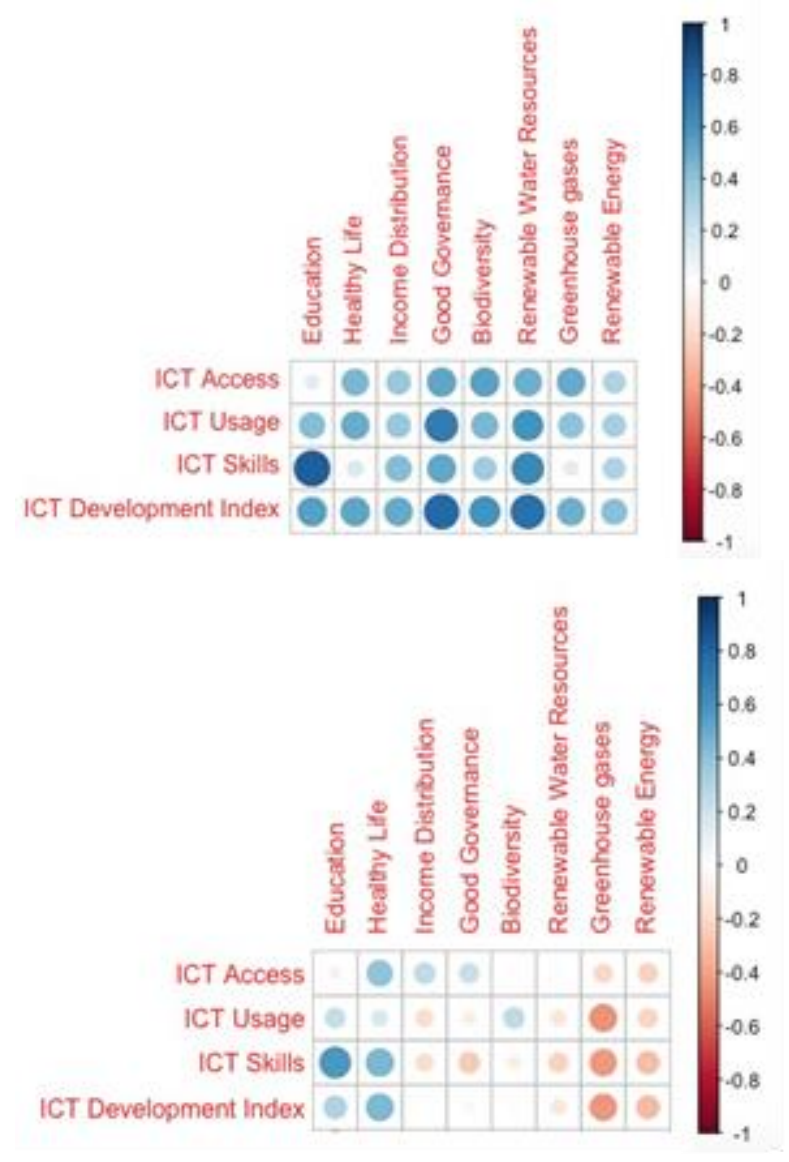

Figure 2: Correlograms for high- (Top) and low(bottom) income countries

The healthy life indicator showed a moderate relationship with overall ICT development in highincome economies. Although there are trade-offs such as electromagnetic radiation and $\mathrm{CO} 2$ emissions, increased information access, storage, and analytics helps in the better decision-making in government, companies, and medical institutions, to mention just a few. Countries with high degrees of economic development are in a better position to harness these informational and communicational facilities to analyze health-based information, offer technical support, and thereby, increase health and longevity. [4] also opines that countries with increased ICT diffusion actually exhibit higher magnitudes of human development (education, health, and income) with increased ICT development.

The moderate correlation of the healthy life indicator with ICT development indicates that advancements in health care owing to ICT contribute to longer life spans in low-income economies. An increase in overall human development occurs thanks to ICT, excluding other external factors. [6] indicates that situational contexts like policies and demands should also be taken into account regarding improvements. People living in low-income countries have needs like those in high-income countries; nonetheless, the needs are not necessarily met like those of people living in high-income economies. A insightful study by [4] prescribes the varying magnitudes of ICT development on human development. The higher the magnitude of ICT development, the higher the magnitude of human development.

Income distribution shares a moderate relationship with ICT development. That is, advances in technology reduce income inequality. On the other hand, countries with less inequality can possess the means for greater ICT diffusion, access, and usage. Income levels make ICT more affordable as the money can be spent on a greater number of possibilities. With less inequality, ICT can be diffused to a larger demography as opposed to it being diffused only to the upper classes. On the other hand, low-income economies do not necessarily show any correlation with increased ICT diffusion.

Increased ICT development could lead to data being gathered on an enormous scale. This also includes data collected to gauge genetic, species, and ecosystem diversity in a country. High-income countries, with increased ICT development, are in a position to gather data to solve problems regarding the rate at which forest and land areas are impacted by various policies. Hence, a relationship exists between ICT development and biodiversity in high-income economies. Some scholars suggest using the lens of the dematerialization of goods - that is, electronic means replacing physical material devices. However, with the rebound effect, these low-priced e-books, music, and video streaming would cause internet consumption to increase resulting in increased energy consumption, which means monetary savings invoked by ICT development would cause environmental issues as the demand for energy increases. Again, there have been studies involving the promotion of e-commerce and teleshopping, which could potentially alleviate the impact of transportation services.

Good governance shows a strong positive relationship with ICT development. ICT acts as a conduit for political awareness, reduces corruption, and offers a platform where efficient economic and political development can take place by fostering governmental accountability and raising awareness among citizens of the political and social forces.

[17] found that when contextual policies and political and administrative factors are considered, the 
country can, in effect, lead to an efficient formation of e-governance. In low-income countries, it is unclear if governance will successfully materialize as indicated by the results. Specifically commenting on African egovernance, the study concluded that, without considering various situational aspects that influence governance, many countries chosen as low-income economies possibly overlook other situational political and administrative factors that thwart them in achieving good governance.

Renewable water sources are again linked, by a moderate degree, to ICT development, as the latter contributes to the analysis and awareness of water generated through the hydrological cycle. Greenhouse gases showed a positive correlation with ICT development. This implies that countries with higher technological development were in a position to quickly adopt sustainable energy measures rather than resorting to traditional power generation methods like burning fossil fuels [27]. It is noted that developed countries emit larger amounts of greenhouse gases, but the trend states that the usage of ICT is bound to increase the value of the variable, meaning less $\mathrm{CO} 2$ emissions. As indicated by [5], there are still innumerable parameters that can help in alleviating the magnitude of environmental impacts besides renewable energy consumption. They include the employment of ICT for energy savings, the management of waste products, and the responsible consumption of energy [7]. Switzerland, Sweden, and Iceland showed high levels of ICT developments and fewer GHG emissions. Developed economies are better able to harness the advantages of adopting sustainable energy resources, and an increase in ICT development contributes to the adoption of renewable energy sources. This has a negative impact on GHG emissions as the more renewable energy is consumed, the less the $\mathrm{CO} 2$ emissions. As posited by [27], developed countries are more likely to adopt sustainable energy methods to alleviate environmental impacts. However, biodiversity and renewable water resources showed almost no correlation with ICT development in low-income countries.

Greenhouse gases and renewable energy show a moderate negative correlation with overall ICT development in low-income economies. The consumption of technology demands more energy, which means that more fossil fuels are burnt, thereby causing more $\mathrm{CO} 2$ emissions. This has a negative effect on environmental well-being and causes environmental degradation, global warming, and climate change. This factor can be alleviated when countries adopt sustainable energy resources as opposed to traditional power generating mechanisms like fossil fuels (it should be noted that underdeveloped economies are at a disadvantage when it comes to the adoption of sustainable energy sources, meaning that improvements in ICT can lead to environmental degradation if energy is not astutely produced). The data showed that Zimbabwe has the highest ICT development of the countries examined, and at the same time emits the highest amount of GHG emissions. Zimbabwe should therefore try to alleviate environmental impacts by adopting sustainable resources. [27] further indicates that ICT acceleration can be slowed down in less developed countries through technology transfers; however, in contradistinction to high-income economies, lowincome economies exhibit opposite behavior in terms of GHG emissions and renewable energy adoption, implying that ICT development may not always necessarily lead to increased renewable energy adoption. [11] promotes the idea of green ICT adoption for developing countries so as to reduce environmental impacts as both ICT development and the need for economic growth lead to increased GHG emissions. Another option is to impose tax regimes on carbon emissions/energy consumption [15], which could suppress people's frivolous usage of resources. This applies to both high-income and low-income countries that are striving to alleviate environmental impacts.

\section{Theoretical contributions and policy implications}

It is evident that ICT diffusion brings both negative and positive effects depending on how it is used. For instance, [27] suggests that underdeveloped or lowincome nations accelerate ICT development through technological transfer, claiming that ICT fostering nations are much more inclined to adopt renewable energy sources. However, the historical data reveal that acceleration in ICT development in low-income economies is actually causing more GHG emissions and less usage of renewable energy, making other situational anomalies come into play. For instance, [10] claim that an increase in awareness, policy regulations, funding, cooperation, and participation could alleviate the negative effects that thwart sustainable development from flourishing. On the other hand, lowincome economies could also alleviate environmental degradation by focusing more on fundamental needs rather than on competing for economic growth. If not, developing countries that have the means to employ ICT projects should gravitate towards green ICT methods for improving energy efficiency [11] and also ICT-supported applications that aid in energy savings [5], waste management [16], and other urban utilities. 
Another interesting research finding by [28] suggests that sustainability owing to ICT diffusion is linked to an information culture, ICT management, and the quality of ICT adoption. Furthermore, it is also important to be responsible when it comes to striking a balance between ICT growth and usage. Irresponsible consumption could outweigh any methods that strive to foster energy efficient methods [7]. Unnecessary usage should be avoided as is claimed by [3], who points out that a lot of energy is wasted on the frivolous use of resources. In short, although ICT has a beneficial impact on education and a healthy life, the alarming rate at which resources are consumed should be taken into consideration so as to alleviate the effects of environmental degradation. Furthermore, [15] provides support that policies in terms of carbon taxing and imposing heavy prices on energy intense ICT devices and energy usage could also lower impacts.

Many developing economies struggle to reconcile growth with sustainability in the context of the UN's 17 SDGs. The narrative developed in the course of our research suggests some policy nuances. For example, while our analyses suggest that high-income nations are in a position to propel most of the goals by harnessing ICT to solve sustainability problems, lowincome countries have exhibited negative reactions towards Goal 7 (Clean Energy) and Goal 13 (Climate Action) with increased GHG emissions and decreased renewable energy production and towards Goal 16 (Governance) in terms of having no impact on ICT development. [8] talks about improvements in education, the empowerment of women, economic productivity, and ICT access (Goals 4, 5, 8, and 9) by taking the case of Ecuador. This indicates that public policy, accessibility, structural strategic planning, etc. are all important in looking for improved solutions. Similarly, in order to circumvent negative reactions towards climate-change-related goals put forth by the UN, governments of low-income economies should strive for policy improvements and strike a balance between technological growth and sustainable development to avoid the further debilitation of the environment. As exemplified by the outputs of lowincome countries, ICT growth showing much less correlation with good governance indicates that public policy and the adoption of such policies and influences need to be central in the public discourses.

\section{Concluding remarks}

This article has hence presented a data-driven narrative of a macro-economic perspective of 39 economies. Micro effects that drive these indicators and countries are not taken into account as the results imply only the overall trends from the historic secondary data. There are several situational anomalies that might inhibit a country from achieving sustainable growth, and these may include influences in terms of policy, political regulations, the context of the country (its geography, demography, land area, population, etc.), the increased need for more resources, the lack of awareness, and the thoughtless use of resources. These anomalies are also dependent on the context of the country in consideration, and the factors that influence one country may not necessarily be attributed to another country. However, the overall global trend of ICT diffusion and its effects are worth considering.

Our narrative corroborates that ICTs could have a direct impact on sustainable growth and emerge as being highly influential in terms of the human wellbeing and environmental well-being dimensions of the SSI [23]. These include education, health, income distribution, governance, biodiversity, greenhouse gas emissions, and renewable energy usage. The definitions of ICT and SSI were discussed along with the mechanisms through which they are calculated [24]. The study is based on the industry standard CRISPDM methodology for delivering a data-driven narrative on the influence of ICT on sustainable growth. The methodology proved to be effective as it was flexible, robust, and offered deeper understanding in executing and performing the various tasks that comprise the data analytics process.

Data-driven narratives serve as a template checklist that enable the traversing of all the facets of data mining and analytics. In the domain of policy development, it is instructional that awareness filters downwards from expertise and comprehension and, in turn, contributes meaningfully to data-driven decisions. The idea of a value hierarchy corroborates with the data value pyramid proposed in the literature.

Figure 3, adopted from [8], illustrates ICT and the data value pyramid. The countries studied were moderated by income levels to understand the similar/disparate behavior of ICT's effects on sustainability. Correlation analysis reveals the disparate behavior of ICT in high-income and lowincome economies. On the one hand, for high-income economies, there are positive effects like increased education enrolment levels and life expectancy, less income inequality, good governance, good proportions of forest and land areas, increases in renewable resources for energy production, and thereby, fewer greenhouse gas emissions on account of increased ICT development. But, on the other hand, there is negative behavior in terms of sustainable growth when it comes to low-income economies. What brings about this difference? Based on our empirical findings, we theorize that a significant gap remains regarding digital literacy (awareness), regulatory policies 
(comprehension), and technological capabilities (expertise) between developed and underdeveloped economies, which leads to the positive and negative outcomes of ICT, respectively. Consequently, the development of literacy, governance, and capabilities is a necessary prerequisite to the effective exploitation of ICT for sustainability. This has been referred to as a maturity model for development by [20]. narrative is suggested as further research. For example, narratives of ineffectual ICT greening, digital pollution, feeding hedonistic growth models and entrenching disparities between OECD and developing economies are worthy of scholarly and policy attention.

Overall, our findings suggest that ICT diffusion has behaved differently in high-income and low-income economies. This highlights the ideas of responsible

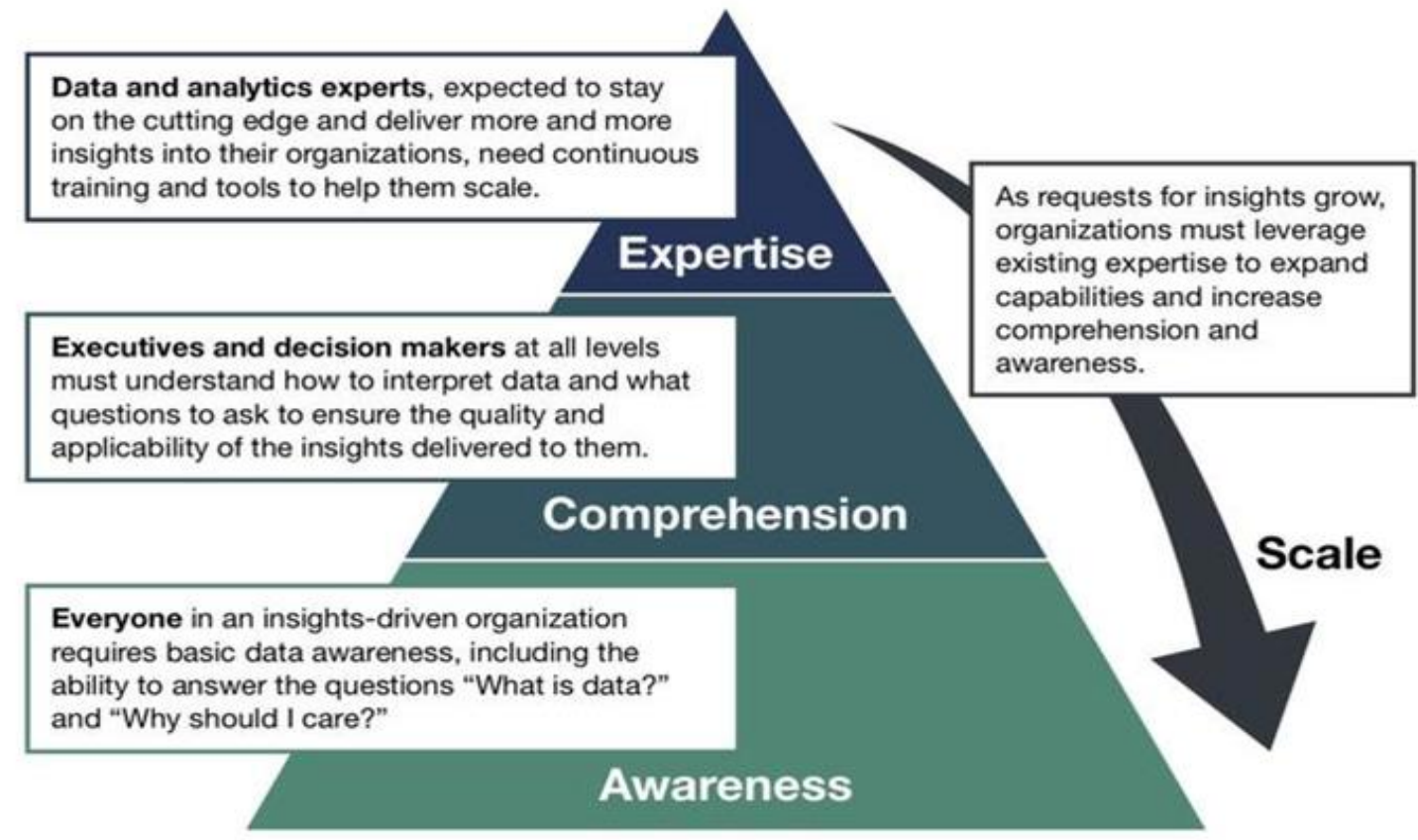

Figure 3: ICT and the data value pyramid

Although educational enrolments and life expectancy show a moderate positive influence with regard to increased ICT development, there is almost no correlation when it comes to income inequality, governance, and biodiversity. [21] points out other causes such as digital enterprise and innovation. There has been an increase in greenhouse gas emissions and a decrease in the employment of sustainable energy sources with increased ICT diffusion, implying that growth in ICT development does not necessarily translate to a sustainable world in low-income economies, unless other external situational factors are taken into account. [15] suggestions of carbon taxing and increasing the prices of fossil fuel consumption could also lower a country's usage of resources and alleviate environmental impacts.

The smart contribution of ICT and particularly artificial intelligence is an important part of the $4^{\text {th }}$ industrial revolution. While this paper presents a positivist account; a more nuanced, interpretivist consumption, technology transfer, efficient green ICT implementation [16], and policy regulations [11] as suggestions for further work. In conclusion, while [26] believes that ICT4D can be considered to be of great significance, he postulates that in spite of its unprecedented spread, there are still many questions to which we do not have clear answers. This paper investigates a method of determining such questions and solutions for sustainable development. Narratives allow the deeper probing of nuances to understand otherwise conflicting or ambivalent empirical findings

\section{References}

[1] Asongu, S.A., and Le Roux, S., "Enhancing ICT for inclusive human development in Sub-Saharan Africa", Technological Forecasting and Social Change, 118, 2017, 44-54, ISSN 0040-1625.

[2] Avgerou, C., "Discourses on ICT and Development", Information Technologies \& International Development, 6 (3), 2010, 1-18.

[3] Bekaroo, G., Bokhoree, C., and Pattinson, C., "Impacts of ICT on the natural ecosystem: a grass-root analysis for promoting socio-environmental sustainability", 
Renewable and Sustainable Energy Reviews, 57, 2016, 1580-1595, ISSN 1364-0321.

[4] Cortés, E.A., and José-Luis, A.N., "Do ICT influence economic growth and human development in European Union countries?" International Advances in Economic Research 17 (1), 201, 28-44.

[5] Casal, C.R., Christine, V. W., Luis, D. S., Burgelman, J. C., and Desruelle, P., "How will ICTs affect our environment in 2020?", Foresight, 7 (1), 2005, 77-87.

[6] Hamel, J.-Y., "ICT in the Human Development Dimensions of Health, Education and Income", Indian Journal of Human Development, 6 (1), 2012, 67-84.

[7] Heddeghem, W.V., Lambert, S., Lannoo, B., Colle, D., Pickavet, M., and Demeester, P., "Trends in worldwide ICT electricity consumption from 2007 to 2012", Computer Communications, 50, 2014, 64-76, ISSN 0140-3664.

[8] Ibujés-Villacís, J.M.; Franco-Crespo, A., "Use of ICT and its relationship with the Objectives of Sustainable Development in Ecuador", RetosRev. De Cienc. De La Adm. Y Econ., 9 (17), 2019, 37-53.

[9] International Telecommunications Union, "The ICT Development Index", 2019, Geneva. Retrieved 14 Sep 2019 from: https://www.itu.int/en/ITUD/Statistics/Documents/ statistics/ITU_ICT\%20Development\%20Index.pdf.

[10] Suryawanshia, K., and Narkhedeb, S., "Green ICT for Sustainable Development: A Higher Education Perspective". Proceedings of the 4th International Conference on Eco-friendly Computing and Communication Systems. In: Procedia Computer Science 70, 2015, 701-707.

[11] Khan, N., Baloch, M.A., Saud, S., and Fatima, T., "The effect of ICT on $\mathrm{CO} 2$ emissions in emerging economies: does the level of income matters?" Environmental Science and Pollution Research, 25 (23), 2018, pp 22850-22860.

[12] Kleine, D., and Unwin, T., "Technological Revolution, Evolution and New Dependencies: what's new about ICT4D?" In Third World Quarterly, 30 (5), 2009, 1045-1067. London: Routledge.

[13] Qureshi, S., "Are we making a Better World with Information and Communication Technology for Development (ICT4D) Research? Findings from the Field and Theory Building", Information Technology for Development, 21 (4), 2015, 511-522, DOI: 10.1080/02681102.2015.1080428

[14] Rostow, W., The stages of economic growth: a noncommunist manifesto, London: Cambridge University Press, 1960.

[15] Røpke, I., and Christensen, T.H., "Energy impacts of ICT - Insights from an everyday life perspective", Telematics and Informatics, 29 (4), 2012, 348-361, ISSN 1877-0509.

[16] Ruth, S., "Reducing ICT-related Carbon Emissions: An Exemplar for Global Energy Policy?", IETE Technical Review, 28 (3), 2011, 207-211.

[17] Schuppan, T., "E-Government in developing countries: experiences from sub-Saharan Africa", Government Information Quarterly, 26 (1), 2009, 118-127, ISSN 0740-624.
[18] Seegolam, A., Sukhoo, A., and Bhoyroo, V., "ICT as an enabler to achieve sustainable development goals for developing countries: A proposed assessment approach. eChallenges e-2015 Conference Proceedings Paul Cunningham and Miriam Cunningham (Eds) IIMC International Information Management Corporation, 2015. ISBN: 978-1-905824-53-3.

[19] Sharma, R.S., Iqbal M.I.N.A., and Victoriano, M.M., "On the use of benchmarking and good practices for knowledge management for development", Knowledge Management Research \& Practice, 11 (4), 2013, 346360 .

[20] Sharma, R., Malone, L., Chong, G., and Dattakumar. A., "A maturity model for digital literacies and sustainable development." Encyclopedia of Information Science and Technology (4th ed.). IGI Global, Hershey, New Jersey, 2018.

[21] Sharma, R., "Revisiting the Knowledge Gini Coefficient: Digital Literacies and Sustainable Development" IT Professional, 20 (5), 2018, 91 - 95. IEEE Computer Society. https://doi.org/10.1109/MITP.2018.053891343

[22] Sharma, R., and Ravindran, T., "The Epistemological Basis for Constructing Data-Driven Narratives", Cambridge Open Engage, 2020, https://doi.org/10.33774/coe-2020-v0cfc

[23] Tjoa A.M., and Tjoa S., "The Role of ICT to Achieve the UN Sustainable Development Goals (SDG). In: Mata F., Pont A. (eds) ICT for Promoting Human Development and Protecting the Environment. WITFOR 2016. IFIP Advances in Information and Communication Technology, 481. Springer, 2016. Cham ISSN 0736-5853.

[24] Van de Kerk, G., and Manuel, A.R., "A comprehensive index for a sustainable society: The SSI — the Sustainable Society Index", Ecological Economics, 66 (2-3), 2008, 228-242, ISSN 0921-8009.

[25] Walsham, G., and Sahay, S., "Research on information systems in developing countries: Current landscape and future prospects", Information Technology for Development, 12(1), 2006, 7-24.

[26] Walsham, G., "ICT4D research: reflections on history and future agenda" Information Technology for Development, 23 (1), 2017, 18-41, DOI:10.1080/02681102.2016.1246406.

[27] Yan, Z., Shi, R., and Yang, Z., "ICT Development and Sustainable Energy Consumption: A Perspective of Energy Productivity", Sustainability, 10 (7), 2018, 115. MDPI AG.

[28] Ziemba, E., "The Contribution of ICT Adoption to the Sustainable Information Society", Journal of Computer information Systems, 59 (2), 2019, 116-126, DOI: 10.1080/08874417.2017.1312635. 